\title{
A Teaching Process of Fostering Students' Problem-solving Skills: A Case Study of Teaching the Equation of a Line
}

\author{
Nguyen Phu Loc ${ }^{1}$, Bui Phuong Uyen ${ }^{1}$, Duong Huu Tong ${ }^{1, *}$, Ha Thien Ngoi ${ }^{2}$ \\ ${ }^{1}$ School of Education, Can Tho University, Vietnam \\ ${ }^{2}$ Tran Van Thoi High School, Ca Mau Province, Vietnam
}

Received March 21, 2020; Revised April 8, 2020; Accepted April 19, 2020

Copyright $\odot 2020$ by authors, all rights reserved. Authors agree that this article remains permanently open access under the terms of the Creative Commons Attribution License 4.0 International License

\begin{abstract}
Teaching mathematics is typically designed to develop the skills of learners, including problem-solving skills. Practice requires teachers to use effective teaching processes to bring the necessary mathematical skills back to the students. In many teaching models, attention must be paid to the lesson study model, which originated in Japan, because it has many educational meanings. This research aims to deploy a teaching process that promotes students' problem-solving skills to solve two mathematical problems in writing straight-line equations. The study used the model of a lesson study to do this. Two classes, including 74 students, have been selected for the control and experimental groups. For the first time, a lesson plan was taught in the control class; then it was thoughtfully adapted and taught for the second time in the experimental class. The data was based on the students' worksheets in two classes and qualitatively analysed to show progress in the teaching process. The findings indicated that the teaching process of the teacher's straight-line equations has led to a positive change in the ability of students to solve problems in the experimental class. These results also revealed more about the effectiveness of a lesson study model. Besides, some implications related to the professional development of teachers in teaching experience have been drawn up, such as teaching practice, competence, assessment skills and the lesson study team.
\end{abstract}

Keywords Equation of a Line, Problem-solving Skill, Mathematics Education, the Teaching Process

\section{Introduction}

Mathematics in high schools contributes to the formation and development of fundamental knowledge, skills, moral qualities, and personality of students, creating opportunities for students to experience and apply mathematics in real life, building a connection between mathematical ideas, mathematics and practice, between mathematics and other subjects. In particular, students need to form and develop mathematical competencies. Among them, mathematical problem-solving skills play an essential role in acquiring learners' mathematical knowledge. To formulate problem-solving skills for students, teachers need to help them know how to think, analyse and explore to identify the conditions, given data, factors to find, relationships, and the system between facts and circumstances. Besides, the teachers need to help students generalise the general form of the problem and give steps to solve the problem.

In his research, E. Ersoy [5] trained prospective teachers in elementary schools about the steps to solve Polya's problem. Positive results were associated with the development of their problem-solving skills. Besides, M. G. Gurat [6] also gave three strategies to develop these skills of teachers such as cognitive, metacognitive and other strategies. These strategies brought a meaningful influence on the teacher's educational performance. In the meantime, S. Saygili [12] discovered the student's solving approach for non-routine problems such as making a systematic list, looking for patterns, logical reasoning and creating a model or diagram. Results were speculated that students performed very well thanks to the effectiveness of these strategies.

In their study, the author J. NoprianiLubis et al. [11] explored the ability of 8th-grade students to solve problems about linear equations and inequalities. The components of problem-solving skills included understanding the problem, planning the problem and 
reviewing the results. However, R. E. Simamora et al. [13] emphasised the effectiveness of discovery-based learning materials which aimed at students' ability and self-efficacy to solve problems. From here, the authors suggested that teachers needed to prepare useful learning materials and pay attention to the local culture in mathematics education-similarly, M. Pd. Zulyadaini [17] used a creative problem-solving learning model to promote students' ability to solve problems. The research results reported that the use of this model brought a significant effect compared to the direct learning model.

The transfer of mathematical knowledge depends on many teaching methods and techniques of teachers, and its reason is due to their interests. In M. Ünal's research [16], teachers preferred techniques such as "question and answer" and "demonstration" because of their ease of use. In contrast, "scenario" and "case study" were not liked by many teachers because they required much preparation time and teaching materials. Also, A. Takahashi et al. [14] emphasised a meaningful role in developing and extending effective mathematics teaching practice because teachers played a central role as investigators for their teaching practices in classrooms. The lesson study, meanwhile, makes an important contribution to the teacher's learning by providing them with specific examples of teaching practice, and this was mentioned in the research of F. Y. Arslan [1].

Meanwhile, N. Boonsena et al. [3] wanted to emphasise the effectiveness of the lesson study's teaching practice. The authors mainly mentioned three critical components such as lesson study team, teaching practices and support. In particular, the preparation and adaptation of each element in each context were crucial. Similarly, Marsitgit [10] mentioned the benefits of lesson study in respects of teaching methods, teachers' competencies, learners' achievements, assessment, learning materials and syllabus. The subject of professional development in the research of F. Coenders and N. Verhoef [4] was beginning and experienced teachers. Lesson study was considered as an activity for Japanese teachers sharing problem-solving approaches. Indeed, M. Isoda [7] was interested in teaching how to learn and sharing pedagogical content knowledge. Moreover, the promotion of teachers' quality through lesson study in the Philippines was also studied by L. Lomibao [9]. The study results were documented that most teachers were positively aware of the benefits of lesson study and that it promoted their career development. Nevertheless, lesson studies do not always bring positive results for teachers; specifically, the research of $\mathrm{R}$. Bjuland and R. Mosvold [2] was a negative case. The results of their study indicated that prospective teachers did not establish research questions for their research lessons, focused on observing students' learning, and their experiences did not make students aware clearly.

\section{Mathematical Problem, Problem-solving, the Teaching Process of Fostering Students' Problem-solving Skills}

\subsection{Mathematical Problem}

According to the author N. P. Loc [8], problems in high schools can be divided into three main categories as follows: Basic problems, advanced problems, practical problems.

Basic problems: Problems that students can directly apply concepts, theorems, algorithms available to solve or problems with not high complexity, are familiar mathematical forms that the strategy addresses almost possible. Math problems of this type are frequently used to reinforce, practise using the knowledge that students have just learned or used to practise a specific skill.

Advanced problems: Problems that the solver does not know how to find the solution; It requires the solver to explore or to use the "trial-and-error" method to find an appropriate explanation for a given problem.

Practical problem: It is a problem put in a specific context, containing a question related to life or related to different fields of science and technology. These problems help students see the applicability of mathematics, and they contribute to motivating students to study mathematics well.

The mathematical problems play an important role in contributing to the implementation of the objectives of math teaching and personality development of learners. The problem creates conditions for students to consolidate the knowledge they have learned, systematise the mathematical knowledge, and practice necessary math solving skills. The problem is also a tool to serve the teaching and learning activities of some other subjects. Furthermore, the problem has the effect of contributing to the formation and development of current intellectual capacity such as analysis, proof, comparison, synthesis, evaluation, generalisation, expansion of the problem practice for students on carefulness, accurate calculation, science, ability to calculate quickly, logical reasoning.

\subsection{Problem-solving}

Problem-solving skill is the ability to apply mathematical knowledge to solve exercises (by reasoning and proving). In math "Skills are the ability to solve problems, perform proofs and critically analyse the solutions and proofs received". Opinions on problem-solving skills of author N. P. Loc [8] are as follows: "Including skills to identify information related to a given problem and handle them to give solutions to the problem". The development of mathematical problem-solving competence is being focused on teaching 
mathematics in Vietnam, and that is made clear in the research of D. H. Tong et al. [15].

Mathematical problem-solving skills include skills to identify information related to a given problem, processing them to provide solutions to the problem. Therefore, math problem-solving skills include the following skills:

Information gathering: Analyse of the problem to show the given information, identify the requirements of the problem, determine the problem type from the facts of the problem, contact the relevant information. For example, the problem about triangles, the information required to connect is the three-point rule (vector), cosine theorem, sine theorem, area, circumference. Therefore, the solvers have a general picture of the problem and obtain the necessary information to find the solution to the problem.

Information processing: Exploiting and transforming collected information, applying known experience and knowledge to find solving strategies.

Aggregation: Aggregating information obtained from information collection and processing. From the discovered solution strategy, use obvious inference to present the logical solution. General skills include skills of organising or organising information, applying deduction, presentation and interpretation of problems.

Evaluation: Assess various information and solution strategies to choose the most feasible and reasonable solution, evaluate solutions to identify missing and unreasonable points to adjust and supplement.

Generalisation: Generalisation, extending problems, giving algorithms.

According to G. Polya (cited by N. P. Loc [8]), a process proposed included four steps for solving a problem:

Step 1: Analyse the problem.

Step 2: Find a solution strategy.

Step 3: Present the solution.

Step 4: Check and study the solution.

To apply Polya's process well in solving problems, we need to give some suggestions in each of the following steps:

- $\quad$ Analyse the problem.

The solver uses some of the following questions to analyse, find out and identify problems such as What did the problem give? What are the requirements of that mathematical exercise? What type of activity is the problem? What is the goal of the problem? How is the problem related to a known problem? Can the problem be repeated into another more straightforward question? Can students give some specific examples to understand the problem better?

\section{- $\quad$ Find solution strategies.}

To find strategies for solving problems, the teacher can use some of the following suggestions such as predicting and testing, solving problems more simply, considering exceptional cases, using interpretation and using analysis. Also, they can start from what students are looking for or prove to find a solution strategy, and convert the problem into a familiar problem. They can solve similar problems, set up an equation, break down the problem, tabulator, experiment, find the form, use variables, change the view, change the approach to the problem, use the formula and use drawings or diagrams.

- $\quad$ Presenting the solution

Make the plan outline, add or adjust the plan as needed.

- Check and study the solution

Review deductive operations; Review the used formulas; Check the calculation; Check the results of the problem; Consider whether the solver has answered the questions posed? Is the solution reasonable? What solution can methods be applied? What can students learn by solving math problems? Solve the same problem? Can students generalise the problem? Can students expand the problem?

\subsection{The Teaching Process of Fostering Students' Problem-solving Skills}

The model of lesson study is originated from Japan; this model is considered as a professional development model of teachers right in the classroom through activities such as planning, lesson observation, discussion, and evaluate the lesson.

The process of teaching and researching lessons includes seven steps as follows:

Step 1: Make a teaching plan.

Step 2: Implement teaching and observing lessons.

Step 3: Analyze, comment, evaluate the lesson that has been taught (first time).

Step 4: Modify the lesson plan, add suggestions, and open questions to suit the students.

Step 5: Implement the lesson plan for the second time.

Step 6: Analyse, comment, evaluate the lesson taught (second time).

Step 7: Apply the experience in the teaching process.

\section{Materials and Methods}

\subsection{Participants}

The researchers chose class 10C7 as an experimental class to teach for the first time; class $10 \mathrm{C} 3$ was a trial class to show the second time of Tran Van Thoi high school, Tran Van Thoi district, Ca Mau province, Vietnam. The two classes 10C3 and 10C7, had the same academic performance, which was reflected in the results of the first-semester Mathematics, the academic year 2018 - 2019. The researchers tested the $\mathrm{H} 0$ statistical hypothesis by the Z-test method with the following significance level 
$\alpha=0.05$ :

Hypothesis H0: The learning ability of two experimental classes is equivalent to each other.

Table 1. The parameters of $z$

\begin{tabular}{|c|c|c|c|}
\hline Classes & Medium score & Number of students & Variance \\
\hline $10 \mathrm{C} 3$ & $\overline{X_{1}} \approx 5.7$ & $N_{1}=37$ & $s_{1}^{2} \approx 2.4903$ \\
\hline $10 \mathrm{C} 7$ & $\overline{X_{2}} \approx 5.9$ & $N_{2}=37$ & $s_{2}^{2} \approx 1.7543$ \\
\hline
\end{tabular}

The data obtained from Table 1 allowed calculation of $|Z| \approx 0.5905$. Because there was $|Z|<Z_{0.05}=1.6449$, the hypothesis $\mathrm{H} 0$ was accepted.

\subsection{Research Design}

The researchers conducted experimental teaching under the model of lesson study, and the design was carried out as follows:
Step 1: Make a teaching plan.

Based on the objectives of the lesson, including knowledge, skills and attitudes, the researchers designed the lesson to achieve the set goals as students write a straight line equation that satisfies the given condition.

Based on the actual situation of the experimental classroom.

Preparation: Teachers prepare lesson plans, computers, projectors, study cards, ruler, phone.

Teaching time: First experimental teaching (class 10C7, lesson 2, March 9 2019). Second experimental teaching (class 10C3, period 5, March 12 2019).

The content of experimental teaching is passed through subject teachers, professional leaders and school leaders:

Problem 1: Write the general equation of the line passing through two points $A(1 ; 2)$ and $B(3 ;-1)$.

Problem 2: Given the line $d: 3 x+4 y-6=0$. Write the equation of the line $\Delta$ parallel to $d$ and with a distance of 2 from $d$.

Table 2. The teaching process of solving problem 1

\begin{tabular}{|l|l|}
\hline Teachers' activities & Students' activities \\
\hline Introduce to students the form of sample problems & Students subscribe, read the content of the problem \\
\hline Ask students to find solutions to sample problems & Students complete the worksheet No. 1 \\
\hline Students restate the model solutions logically & Students complete the worksheet No. 2 \\
\hline Students form general mathematical statements and provide solutions & Students complete the worksheet No. 3 \\
\hline Students practice solving problems of the same type. & Students complete the worksheet No. 4 \\
\hline Adjust the model (if needed). & Students follow the requirements of teachers. \\
\hline
\end{tabular}

Table 3. The teaching process of solving problem 2

\begin{tabular}{|l|l|}
\hline Teachers' activities & Students' activities \\
\hline Teachers ask students to analyse the problem & Students complete the worksheet No. 5, 6 \\
\hline Teachers ask students to find solution strategies. & Students complete the worksheet No. 7 \\
\hline Teachers ask students to present the solution. & Students complete the worksheet No. 8 \\
\hline Teachers ask students to check and study the solution & Students comment, follow up, take note. \\
\hline
\end{tabular}


Step 2: Teach and observe the lesson (first time - class 10C7).

The researchers conduct teaching solving two problems of writing equations of straight lines with the participation of two teachers.

Conduct teaching according to the procedure (Students work in groups).

- Teacher stable class.

- Teachers divide the class into eight groups (groups of 1 to 5; each group has five students and groups of 6 to 8 each have four students). Each group chooses its leader and secretary.

- Teachers do not check the old lesson.

- Teacher shows the content of problem 1 on the projector, distributes learning cards to students and asks students to do the exercises on the worksheet.

- $\quad$ Students do math problem 1 in 10 minutes.

- Teachers take the results of each group with their phones, show them on the projector. Teacher and student comment together, analyse the answers of the student group (See Table 2).

Conduct teaching according to the procedure (Students working individually).

- Teacher shows the content of problem 2 on the projector, distributes worksheets to students and asks students to do the exercises on the sheet.

- $\quad$ Students do math problem 2 in 10 minutes.

- Teachers use the phone to capture the results of students' work and show it on the projector. Teachers and students analyse, comment, evaluate the answers of students (See Table 3).

Step 3: Analyze, comment, evaluate the lessons that have been taught (first time).

After the first experimental teaching (class 10C7), the researchers conduct analysis, comment, and evaluation.

Step 4: Modify the lesson plan, add suggestions, and open questions to suit the students.

It is necessary to absorb the ideas of teachers who attend the lesson in the first teaching session, supplement the test of the old experience, review, consolidate knowledge for students and adjust lesson plans as follows:

- Content of checking the early test: general equation of the straight line. The relative position of two consecutive lines. The formula calculates the distance from a point to a line.

Step 5: Conduct teaching a second time.
We conduct the second experimental teaching - class 10C3, period five on March 12, 2019, with the participation of two teachers.

Conduct teaching according to the procedure (Students work in groups).

- Teacher stabilises class and checks old lesson.

- Teachers divide the class into eight groups (groups of 1 to 5; each group has five students and groups of 6 to 8 each have four students). Each group chooses its leader and secretary.

- Teacher shows the content of problem one on the projector, distributes learning cards to students and asks students to do the exercises on the worksheet.

- Students do mathematical problem 1 in 10 minutes.

- Teachers take the results of each group with their phones and show them on the projector. Teachers, students analyse together, comment, the answers of the student group.

Step 6: Analyse, comment, evaluate the lesson taught (second time).

After the second experimental teaching (grade 10C3), they conduct analysis, comment, and evaluation.

Step 7: Apply the experience in the teaching process.

The researchers have applied the lesson study model to the teaching of solving problems of straight-line equations and other mathematical problems.

\subsection{Data Analysis}

Qualitative analysis was used in depth to clarify the work of the students. Correctly, the results were analysed and evaluated to show progress in students' problem-solving ability after adjusting lesson plans. Data were students' assignments; they are explained in the comparison of problem-solving capacities of two selected experimental classes. Besides, comments made by two teachers were recorded to analyse the effectiveness of teaching activities.

\section{Results and Discussion}

\subsection{Results of First Experimental Teaching}

For mathematical problem 1: By means of the first innovative teaching, the student response statistics were as follows: 
Table 4. Experimental teaching results of problem 1 in class $10 \mathrm{C} 7$ (first time)

\begin{tabular}{|c|l|c|c|c|}
\hline Worksheets & \multicolumn{1}{|c|}{ Request } & Correct & Wrong & Empty \\
\hline \multirow{2}{*}{1} & Indicate how to write a general equation for a straight line & $\begin{array}{c}3 / 8 \\
(37.5 \%)\end{array}$ & $\begin{array}{c}3 / 8 \\
(37.5 \%)\end{array}$ & $\begin{array}{c}2 / 8 \\
(25 \%)\end{array}$ \\
\hline \multirow{2}{*}{2} & Presentation of the solution to the problem & $\begin{array}{c}2 / 8 \\
(25 \%)\end{array}$ & $\begin{array}{c}4 / 8 \\
(50 \%)\end{array}$ & $\begin{array}{c}2 / 8 \\
(25 \%)\end{array}$ \\
\hline \multirow{2}{*}{3} & Give general math form, steps to solve the problem & $\begin{array}{c}1 / 8 \\
(12.5 \%)\end{array}$ & $\begin{array}{c}3 / 8 \\
(37.5 \%)\end{array}$ & $\begin{array}{c}4 / 8 \\
(50 \%)\end{array}$ \\
\hline \multirow{2}{*}{4} & Do the same type of problem & $\begin{array}{c}1 / 8 \\
(12.5 \%)\end{array}$ & $\begin{array}{c}4 / 8 \\
(50 \%)\end{array}$ & $\begin{array}{c}3 / 8 \\
(37.5 \%)\end{array}$ \\
\hline
\end{tabular}

Through the first teaching results in Table 4, the group of students who answered incorrectly and left blank was five groups (accounting for 62.5\%). This number proved that the student groups had not carefully read the question, did not grasp the content of the item. The majority of student groups had not found a solution to the problem. Therefore, teachers needed to guide students with some solving strategies such as finding points in the line $A B$ as well as normal vectors and writing general equations of the line $A B$. They asked their students to write parametric equations of line $A B$ and transform it to its general equation, writing the regular equation for the line $A B$ and transforming it to its general equation.

The initial instructional outcomes showed that groups of students knew how to write general line equations $A B$, but when applied to the formula, they did not pay attention to the points of the line $A B$. Group of finished students did not check the results by changing the coordinates of points $A$ and $B$ into the general equation of the line $A B$. The student groups focused mainly on solving strategies: Find vectors of straight line $A B$, then write the general equation of the straight line $A B$ (this strategy accounted for $50 \%$ ) and have a solving plan (accounting for $12.5 \%$ ). Suppose that the line $A B$ has an equation, from the two-point data set up a system of first-order equations hidden $a, b$ and then solve the newly established equation system to find $a, b$. The remaining solving strategies: Write the regular equation of the line $A B$ and convert it to its general equation, write the parametric equation of the line $A B$ and then convert to its general equation by reducing $t$. For this question, the student group gave incorrect answers to four groups (accounting for 50\%), the student group left two groups empty (accounting for 25\%). Thus, the group of students wrongly answered and left blank accounted for $75 \%$.

During the first coaching period, groups of students were left with too much vacancy $(50 \%)$, that was, groups of students who did not recognise the problem form and did not give steps to solve a problem. This information proved that students read the problem and then found the solution, less interested in the general form of the problem. Hence, the teacher gave a specific problem and asked students to state its general way; the student faced many difficulties and obstacles in their statement. Some student groups still confused the general form of the problem and the general equation of the line.

From the data achieved, it was found that there was a group of students who were not knowledgeable about finding vector coordinates when knowing points, that was, the group of students did not apply the correct formula.

Group of students had not mastered the knowledge. If the line had a vector of the only direction, then there was a normal vector. When the student group applied the formula, they did not pay attention to the point of the line and its normal vector.

After students solved a problem for a similar problem so that they could explain it to consolidate the knowledge, they had learned. Still, the results of the student's work showed that the application of the learned knowledge to the same problem faced numerous difficulties and errors. 
Table 5. Experimental teaching results of problem 2 in class $10 \mathrm{C} 7$ (first time)

\begin{tabular}{|c|l|c|c|c|}
\hline Worksheets & \multicolumn{1}{|c|}{ Request } & Correct & Wrong & Empty \\
\hline \multirow{2}{*}{1} & Indicate how to write a general equation for a straight line & $16 / 37$ & $18 / 37$ & $3 / 37$ \\
& & $(43.2 \%)$ & $(48.7 \%)$ & $(8.1)$ \\
\hline \multirow{2}{*}{2} & \multirow{2}{*}{ Presentation of the solution to the problem } & $13 / 37$ & $14 / 37$ & $10 / 37$ \\
& & $(35.1 \%)$ & $(37.9 \%)$ & $(27 \%)$ \\
\hline \multirow{2}{*}{3} & \multirow{2}{*}{ Give general math form, steps to solve the problem } & $7 / 37$ & $16 / 37$ & $14 / 37$ \\
& & $(18.9 \%)$ & $(43.2 \%)$ & $(37.9 \%)$ \\
\hline \multirow{2}{*}{4} & \multirow{2}{*}{ Do the same type of problem } & $6 / 37$ & $15 / 37$ & $16 / 37$ \\
& & $(16.3 \%)$ & $(40.5 \%)$ & $(43.2 \%)$ \\
\hline
\end{tabular}

Based on the data in Table 5, the students who answered incorrectly were 18 students (accounting for 48.7\%), meaning that many students finished reading the content of the problem without identifying and analysing to solve the problem. In the first teaching practice, most students had not yet analysed the content of the issue, i.e. they did not know what the problem has given? The facts of the problem? What do they need to look? So most students only recorded the content of the problem.

The data received revealed that most students could not find strategies to solve problems. Students had not exploited all the data of the problem but only utilised a few data. For example, a normal vector of a line $\Delta$ is obtained using straight-line data $\Delta$ parallel to line $d$, knowing the distance between two parallel lines equals the distance from one point of this straight line to another. Many students had not taken steps to solve the problem.

Through the initial learning outcomes, students were able to use data from two parallel lines to find the normal vector of a straight line. Students who found the normal vector of a line had two directions to write its general equation.

First, students found the coordinates of a point in a straight line, the general equation of the line had the form. Students exploited straight-line data a distance of 2 but could not solve the equation containing hidden in absolute values signs to find. Second, students found the constant $c$ of the equation $3 x+4 y+c=0$. For this solution, many students had made some mistakes such as lack of conditions of $c$, applying the distance formula from a point to a straight line incorrectly, not solving the equation containing hidden values in the sign absolute.

In summary, through the first experimental teaching, there were some comments and assessments.

For problem 1:

Advantages: Teachers had implemented the process of teaching mathematics to help students practice skills to solve an underlying math problem. Students studied seriously, positively, teamwork, awareness and appropriate discipline.

Limitations: Teachers had not reviewed or re-checked the knowledge that students had learned. Many student groups found the wrong coordinates of the point vector, confused the direction vector and the normal vector of the line. Besides, they also paid little attention to the point of the line, performed calculations with many errors, presented the solution wrong, stated the general form of the problem and stated that the solution steps were much-left blank. Activity applied to solve the issues of the same type had many groups of students not yet implemented.

For problem 2:

Advantages: Teachers had implemented the process of teaching math problems to help students practice skills to solve an advanced problem. Most students identified issues, found the normal vector of straight lines, made beneficial use of the data of two parallel lines, applied the distance formula from a point to a straight line. Students studied seriously, positively, cooperative spirit, awareness and suitable discipline.

Limitations: Teachers had not reviewed or re-checked the knowledge that students had learned. Many students had not yet analysed the problem, which means they have not answered well the questions: What did the problem give? What are the requirements of that math exercise? What are the goals of the problem? ... Students less analysed the problem content but mainly raised the hypothesis of the problem. Most students had not stated how to solve the problem; the presentation of the solution was wrong and left blank too much.

Teachers' comments were as follows:

Teaching teachers should check the old lesson or revise the knowledge that students had learned such as general equations of straight lines and writing general equations of lines that pass through a point and have perpendicular vectors (or vectors) given directions. Besides, they can explain for their students the relative position between two consecutive lines, the distance between two parallel lines, the distance from a point to a straight line, solving equations hidden in the absolute value sign, how to find a solution of the unknown quadratic equation. Teachers should instruct, ask some more provocative questions, make some suggestions in the worksheets by filling in the blank and following the class in the process of students doing the homework.

\subsection{Results of Second Experimental Teaching}

Following the second innovative teaching in class 10C3, it was essential to conduct analysis, comment, and evaluation. 
Table 6. Experimental teaching results of problem 1 in class $10 \mathrm{C} 3$ (second time)

\begin{tabular}{|c|l|c|c|c|}
\hline Worksheets & \multicolumn{1}{|c|}{ Request } & Correct & Wrong & Empty \\
\hline \multirow{2}{*}{1} & Indicate how to write a general equation for a straight line & $\begin{array}{c}7 / 8 \\
(87.5 \%)\end{array}$ & $\begin{array}{c}1 / 8 \\
(12.5 \%)\end{array}$ & $\begin{array}{c}0 / 8 \\
(0 \%)\end{array}$ \\
\hline \multirow{2}{*}{2} & Presentation of the solution of the problem & $7 / 8$ & $1 / 8$ & $0 / 8$ \\
& & $(87.5 \%)$ & $(12.5 \%)$ & $(0 \%)$ \\
\hline \multirow{2}{*}{3} & \multirow{2}{*}{ Give general math form, steps to solve the problem } & $(75 \%)$ & $(25 \%)$ & $0 / 8$ \\
& & $8 / 8$ & $0 / 8$ & $(0 \%)$ \\
\hline \multirow{2}{*}{4} & \multirow{2}{*}{ Do the same type of problem } & $(100 \%)$ & $(0 \%)$ & $0 / 8$ \\
& & & $(0 \%)$ \\
\hline
\end{tabular}

Table 6 showed that seven groups of students (accounting for $87.5 \%$ ) answered the questions correctly. Nonetheless, there was also a group of students (group 7) who correctly answered the question that was to write the general equation of the line $A B$ needs a point in line $A B$ and its direction vector. The group had not yet given from the directional vector of the line $A B$ deduce its normal vector or write the parametric equation (regular equation) of the straight line $A B$ that transformed to its general equation. The student group (group 7) had not specified the strategy for solving the problem.

The teacher had adjusted the lesson plan by reviewing the knowledge of the general equation of the line, the writing of the general equation of the line through the point and the given normal vector so, in this teaching session, the teacher helped students to answer the questions of the teacher posed. However, there was a group of students who lacked an ideal answer.

From the teaching results and analysis of teaching, results showed that the student groups had made progress in learning in the second teaching period. Teachers helped the student group overcome most of the incorrect answers and no longer left the answers blank. The first teaching results only got three groups of students (accounting for $37.5 \%$ ) answered correctly. Still, the second teaching results had seven groups of students (accounting for $87.5 \%$ ) responded correctly (increased by four groups) (accounting for $50 \%$ ).

Through the findings in the second teaching period, there was still a group of students who made mistakes, regardless of the point of the line $A B$. Subjective group of students applied the formula to write a general equation of a line when knowing the point of the line and its normal vector. For this question, the student group that incorrectly answered was one of the student group (accounting for $12.5 \%$ ). The number of groups of students who correctly answered this question at the second teaching time increased by five groups of students (accounting for 62.5\%) compared to the first teaching session.

During the second teaching period in class 10C3, it had been shown that groups of students have expressed the general form of the problem and have provided reasonable solutions. Nevertheless, there was still a group of students who were unable to show the general mathematical structure of the problem but gave the equation form of the line that passed through a given point and had a given normal vector.

Compared to the results of two teaching sessions, it was known that in the second time of teaching, the number of student groups that answered the question correctly was six groups (accounting for 75\%) compared to the first teaching time, an increase of five groups (accounting for $62.5 \%$ ). In the second teaching period (class 10C 3 ), the teacher checked the old lesson, reviewed the learned knowledge and emphasised the relationship between the directional vector and the normal vector of the line. Since then, teachers had helped students overcome many difficulties and errors, resulting in eight groups of students (accounting for $100 \%$ ) to solve the same problem. 
Table 7. Experimental teaching results of problem 2 in class $10 \mathrm{C} 3$ (second time)

\begin{tabular}{|c|c|c|c|c|}
\hline Worksheets & Request & Correct & Wrong & Empty \\
\hline 1 & Indicate how to write a general equation for a straight line & $\begin{array}{c}37 / 37 \\
(100 \%)\end{array}$ & $\begin{array}{l}0 / 37 \\
(0 \%)\end{array}$ & $\begin{array}{l}0 / 37 \\
(0 \%)\end{array}$ \\
\hline 2 & Presentation of the solution of the problem & $\begin{array}{c}34 / 37 \\
(91.9 \%)\end{array}$ & $\begin{array}{c}3 / 37 \\
(8.1 \%)\end{array}$ & $\begin{array}{l}0 / 37 \\
(0 \%)\end{array}$ \\
\hline 3 & Give general math form, steps to solve the problem & $\begin{array}{c}33 / 37 \\
(89.2 \%)\end{array}$ & $\begin{array}{c}4 / 37 \\
(10.8 \%)\end{array}$ & $\begin{array}{l}0 / 37 \\
(0 \%)\end{array}$ \\
\hline 4 & Do the same type of problem & $\begin{array}{c}34 / 37 \\
(91.9 \%)\end{array}$ & $\begin{array}{c}3 / 37 \\
(8.1 \%)\end{array}$ & $\begin{array}{l}0 / 37 \\
(0 \%)\end{array}$ \\
\hline
\end{tabular}

In the second teaching session of class $10 \mathrm{C} 3$, teachers helped students overcome errors and difficulties in answering this question by asking more open questions. The result of students correctly answering this question was 37 students (accounting for 100\%).

According to Table 7, thirty-four students (accounting for $91.9 \%$ ) answered correctly. Nonetheless, there were still two students (accounting for $5.4 \%$ ) who did not answer correctly according to the instructions of the teachers, i.e. students had not been able to analyse the content of the problem, do not know what the problem gave? What does the problem require? The purpose of the problem? Were the facts presented? Students stated the assigned problem of the perpendicular vector, the quadratic vector but did not specify the normal vector, the only vector of the straight line $d$ or the straight line $\Delta$ and what to look for was the coordinates of the directional vector of the straight line $d$. In the second teaching period in class $10 \mathrm{C} 3$, the teacher added some learning suggestions, so the teacher helped the students analyse the content of the problem. The number of students who answered the questions correctly in the second teaching session increased to 21 students (accounting for 56.8\%) compared to the first time of teaching.

Additionally, there were two students (accounting for $5.4 \%$ ) applying the theoretical concept of general equations of straight lines mechanically to write general equations of consecutive lines they found points on straight lines and vectors its gland. For this problem, finding the normal vector of a straight line was relatively easy just using the data of two parallel lines but finding a point in a straight line was very difficult for students. Through the second teaching results (class 10C3), the number of students who correctly answered this question was 33 students (accounting for $89.2 \%$ ). Thus, the number of students who correctly answered this question in the second teaching period increased to 26 students (accounting for $70.3 \%$ ) compared to the first time of teaching.

In summary, after the second experimental teaching session, some comments and assessments were recorded as follows:

Advantages: Teachers had reviewed, re-examined the knowledge they had learned, added some intriguing questions and implemented a process of teaching math problems to help students practice skills to solve a problem. Students studied seriously and actively, with a spirit of cooperation, efficient sense and discipline.

Limitations: Teachers had not overcome all of the mistakes made by students in the first teaching session, such as still looking for the wrong coordinates of the vector $\overrightarrow{A B}$, presenting incorrect answers, solving equations containing hidden in the absolute value sign wrongly, and choosing the optimal solution. Some students were still subjective in applying the formula, not careful in calculating and solving the problem, and rarely checked the results.

Teachers' comments were as follows: Teaching teachers had absorbed the ideas of the teachers for the first time, helping students overcome difficulties and mistakes in the process of solving a problem. The teachers had overcome the limitations and promoted many advantages in the first teaching. The content of checking the old lesson, revision knowledge and reasonable suggestions should make most students understand the lesson and answer the questions that the teacher had asked. However, some groups of students had not yet answered the questions of teachers because they were subjective in applying formulas and calculations.

\subsection{General Evaluation of Experimental Results}

After first creative coaching in class $10 \mathrm{C} 7$, students were still struggling to use the knowledge they learned to solve a problem. The rate of students' answering the questions incorrectly or leaving the answers blank was very high. Teachers taught to analyse, comment, do their homework, absorb the feedback of teachers who attend the lesson, realise the advantages and limitations of teachers and students. Students still lacked much basic knowledge about straight-line equations, the application of learned knowledge to solving problems was still limited. Therefore, the teacher needed to retest the previous lesson, consolidate the basic knowledge for students so that the next experience would achieve better results. In this teaching session, the researchers evaluated that the teachers did not reach the set goals.

On the basis of the outcomes of the second experimental teaching (class 10C3), it could be confirmed that teachers of innovative instruction had succeeded in education according to the model of lesson study. The teacher adjusted some content and methods in the lesson plan to overcome the limitations and promote the advantages of 
the first lesson. The adjustment of the teacher's experience was very suitable for the students' ability, so the quality of the teaching was improved and improved. The teacher also helped students overcome errors and difficulties in the process of solving mathematical problems. Students had much progress in learning and overcame the limitations in the learning process. In this instructional session, the researchers achieved the set goals.

\section{Conclusions and Suggestions}

The research was associated with the experimental teaching of two problems of writing linear equations. The first innovative teaching in class $10 \mathrm{C} 7$ revealed that students still face many difficulties and obstacles in identifying, presenting solutions, making general mathematical statements, and taking steps to solve one lesson. Choosing the optimal solution strategy, performing calculations with many errors and offering the answer was not logical. After the first observational teaching, the innovative education teacher joined the teachers during the meeting and learnt the benefits and limitations of the teaching period. Experimental teaching teachers adjusted the lesson plan by reviewing the knowledge they had gained, adding more suggested questions to suit teaching students. The results of the second experimental teaching in class $10 \mathrm{C} 3$ showed that the students were able to solve the problems the teacher had posed, that the students had overcome the situation of being unable to answer the teachers' questions and the students' errors in the problem-solving process. The quality of the lesson was significantly improved.

In the process of practical teaching, teachers did not impose knowledge for students. Still, the experience that students learnt was the result of the process of activities of teachers and students. Students' ability to think, analyse, reason, compare, comment, and evaluate was developed, overcoming rote learning, studying mechanically. The knowledge that students comprehend was also profoundly engraved. Students applied the knowledge that they had learned to solve problems and practical situations in a flexible way. These results were similar to the ones outlined in the literature review $[6,11,13,15]$.

Moreover, the study brought some implications. Firstly, the teacher, who taught the experimental class, had positive experiences in teaching practice. In particular, they have made more valid assessments of the skills of their students, from which they have adapted teaching plans to suit the problem-solving skills of their students. In other words, the teaching method of teachers has been developed significantly. Secondly, teachers' capacity to solve problems, evaluate and observe teaching period was improved. Finally, the relationships of the same school teachers were strengthened because they helped each other in their professional development. In general, these implications were not different from the studies referred to $[1,2,9,14]$.

\section{REFERENCES}

[1] F. Y. Arslan. The Role of Lesson Study in Teacher Learning and Professional Development of EFL Teachers in Turkey: A Case Study, TESOL Journal, 1-13, 2018.

[2] R. Bjuland \& R. Mosvold. Lesson study in teacher education: learning from a challenging case, Teaching and Teacher Education, Vol.52, 83-90, 2015.

[3] N. Boonsena, M. Inprasitha, N. Changsri \& G. Teachers. Learning about Teaching Practice in a Modify Lesson Study, Psychology, Vol.10, 977-988, 2019.

[4] F. Coenders \& N. Verhoef. Lesson Study: professional development (PD) for beginning and experienced teachers, Professional Development in Education, Vol. 45, No. 2, 217-230, 2019.

[5] E. Ersoy. Problem-solving and Its Teaching in Mathematics, The Online Journal of New Horizons in Education, Vol.6, No.2, 79-87, 2016.

[6] M. G. Gurat. Mathematical Problem-solving Strategies Among Student Teachers, Journal on Efficiency and Responsibility in Education and Science, Vol.11, No.3, 53-64, 2018.

[7] M. Isoda. Lesson Study: Problem Solving Approaches in Mathematics Education as a Japanese Experience, Procedia Social and Behavioral Sciences, Vol.8, 17-27, 2010.

[8] N. P. Loc. Active learning activities of students in teaching Mathematics: A monograph on the basis of operational theory, Publisher of Can Tho University, Vietnam, 2016.

[9] L. S. Lomibao. Enhancing Mathematics Teachers' Quality through Lesson Study, SpringerPlus, Vol.5, No.1590, 1-13, 2016.

[10] Marsigit. Mathematics Teachers' Professional Development through Lesson Study in Indonesia, Eurasia Journal of Mathematics, Science \& Technology Education, Vol. 3, No.2, 141-144, 2007.

[11] J. NoprianiLubis, A. Panjaitan, E. Surya \& E Syahputra. Analysis Mathematical Problem Solving Skills of Student of the Grade VIII-2 Junior High School Bilah Hulu Labuhan Batu, International Journal of Novel Research in Education and Learning, Vol. 4, No.2, 131-137, 2017.

[12] S. Saygili. Examining The Problem Solving Skills and The Strategies Used By High School Students in Solving Non-routine Problems, E-International Journal for the Educational Research. Vol.8, No.2, 91-114, 2017.

[13] R. E. Simamora, S. Saragih \& Hasratuddin. Improving Students' Mathematical Problem-solving Ability and Self-Efficacy through Guided Discovery Learning in Local Culture Context, International Electronic Journal of Mathematics Education, Vol.14, No.1, 197-204, 2006.

[14] A. Takahashi, T. Watanabe \& M. Yoshida. Developing 
Good Mathematics Teaching Practice Through Lesson Study: A U. S. Perspective, Tsukuba Journal of Educational Study in Mathematics, Vol.25, 197-204, 2006.

[15] D. H. Tong, N. P. Loc, B. P. Uyen \& C. L. Truc. A Case Study of Developing Students' Problem-solving Skills Through Addressing Real-World Problems Related to Fractions in Primary Schools, International Journal of Scientific \& Technology Research, Vol.9, No.2, 2809-2818, 2020.

[16] M. Ünal. Preferences of Teaching Methods and Techniques in Mathematics with Reasons, Universal Journal of Educational Research, Vol.5, No.2, 194-202, 2017.

[17] M. P. Zulyadaini. Effects of Creative Problem Solving Learning Model on Mathematical Problem-solving Skills of Senior High School, IOSR Journal of Research \& Method in Education, Vol.7, No.3, 33-37, 2017. 